\title{
A review of analgesic and emotive breathing: a multidisciplinary approach
}

\author{
This article was published in the following Dove Press journal: \\ Journal of Multidisciplinary Healthcare \\ 29 February 2016 \\ Number of times this article has been viewed
}

\author{
Bruno Bordoni ${ }^{1-3}$ \\ Fabiola Marelli2,3 \\ Giovannni Bordoni ${ }^{2,3}$ \\ 'Department of Cardiology, Santa \\ Maria Nascente IRCCS, Milan, Don \\ Carlo Gnocchi Foundation, Milan, \\ Italy; ${ }^{2}$ Department of Osteopathy, \\ Centre de recherche d'emploi du \\ Sud-Ouest (CRESO), Osteopathic \\ Centre for Research and Studies, \\ Falconara Marittima, Ancona, Italy; \\ ${ }^{3}$ Department of Osteopathy, Centre \\ de recherche d'emploi du Sud-Ouest \\ (CRESO), Osteopathic Centre for \\ Research and Studies, Castellanza, \\ Varese, Italy
}

\begin{abstract}
The diaphragm is the primary muscle involved in breathing and other non-primarily respiratory functions such as the maintenance of correct posture and lumbar and sacroiliac movement. It intervenes to facilitate cleaning of the upper airways through coughing, facilitates the evacuation of the intestines, and promotes the redistribution of the body's blood. The diaphragm also has the ability to affect the perception of pain and the emotional state of the patient, functions that are the subject of this article. The aim of this article is to gather for the first time, within a single text, information on the nonrespiratory functions of the diaphragm muscle and its analgesic and emotional response functions. It also aims to highlight and reflect on the fact that when the diaphragm is treated manually, a daily occurrence for manual operators, it is not just an area of musculature that is treated but the entire body, including the psyche. This reflection allows for a multidisciplinary approach to the diaphragm and the collaboration of various medical and nonmedical practitioners, with the ultimate goal of regaining or improving the patient's physical and mental well-being.
\end{abstract}

Keywords: diaphragm, fascia, osteopathic, pain, motions, manual therapy

\section{Introduction}

The diaphragm is the main respiratory muscle that is able to influence, through its contractions, the act of breathing. ${ }^{1}$ It provides good mechanical function of the spine and sacroiliac joint, as well as affecting the working of the pelvic and buccal floor muscles. ${ }^{1,2}$ The diaphragm also facilitates the venous and lymphatic return, works to maintain a balanced posture during several changes of the body positions, allowing the viscera above and below the diaphragm to work properly. ${ }^{2-5}$ The diaphragm works together with various processes such as expectoration through coughing and the actions of vomiting, defecation, and swallowing. ${ }^{2,5}$ The diaphragm muscle plays a key role in health and in the many activities of the human body.

The respiratory diaphragm muscle is innervated by the phrenic nerve (C3-C5) and the vagus nerve (cranial nerve $\mathrm{X}$ ); the first receives pulses from groups of medullary neurons of the pre-Bötzinger complex and neurons of the parafacial retrotrapezoid complex, which in turn receive orders over retroambiguus from the core of the bulb, although the mechanisms that underlie these links are not completely clear. ${ }^{2}$ The vagus nerve is part of the parasympathetic autonomous system originating from the spinal oblongata, and terminates at the nucleus ambiguus. ${ }^{6}$ The phrenic nerve and the vagus nerve anastomose at the neck level. ${ }^{2}$ 
The areas of the brain involved in the control of breathing are different and their activation weight changes depending on the type of breathing, metabolic conditions, and interoceptive and exteroceptive information. ${ }^{7-10}$

The aim of this article is to gather for the first time, within a single text, information on the nonrespiratory functions of the diaphragm muscle: its analgesic and emotional response functions. It also aims to highlight and reflect on the fact that when the diaphragm is treated manually, a daily occurrence for manual operators, it is not just an area of musculature that is treated but the entire body, including the psyche. This reflection allows for a multidisciplinary approach to the diaphragm and the collaboration of various medical and nonmedical practitioners, with the ultimate goal of regaining or improving the patient's physical and mental well-being.

\section{Analgesic respiration}

The perception of pain is diminished if the breath is held after a deep breath, a condition in which the diaphragm is lowered. ${ }^{11}$ This event appears to reflect the involvement of baroreceptors. With this action, the respiratory systolic pressure increases, with a decrease in the cardiac frequency. ${ }^{11} \mathrm{We}$ know that when the baroreceptors situated in the carotid body and the area of the aortic arch in the adventitia of the vessels are naturally stimulated by the cardiac cycle, in particular by the systole, the nociceptive stimulus is attenuated by the activation of the baroreceptors. ${ }^{12}$

The intervention of the baroreceptors affects the muscle tone, as it decreases the activity of the sympathetic nervous system, reducing the contractile tone. ${ }^{12}$ The reduction of pain perception is greater if the subject is aware of the pain itself. ${ }^{12}$ Acute and chronic pain can alter the baroreceptor function and consequently damage the regulatory function of the cardiovascular system; this will lead, in the long run, to an increased risk of morbidity and mortality. ${ }^{13}$

The baroreceptors are structures that are activated if the vessel is stretched by passing blood. ${ }^{14}$ The passing afferents are collected by the nucleus of the solitary tract (NTS), which regulates efferential intervention of the vagal system and the inhibitory sympathetic efferent in the spinal cord near the nucleus ambiguus, the dorsal motor nucleus, and the rostral ventrolateral medulla oblongata area. ${ }^{14}$ Baroceptor afferents affect different areas of the central nervous system, with a generalized inhibitory effect. ${ }^{14}$ The NTS interconnects with the reticular formation, from which information is sent to the front, lateral, and medial prefrontal insula and the anterior cingulate cortex; even the thalamus, hypothalamus, and periaqueductal gray area receive signals from NTS baroreceptors. ${ }^{14}$

There is a close relationship between emotion, respiration, and the intervention of baroreceptors. ${ }^{14}$ Emotional experience influences the response to pain, because the pain response is not simply a neural process started by nociceptive afferents. ${ }^{12}$ Emotional states, such as anxiety or depression, and psychiatric disorders are able to negatively alter the baroreceptor response. ${ }^{15}$ Stress can lead to anxiety and/or depression, resulting in an alteration of the proper functioning of the diaphragm. ${ }^{16}$ Modifications in the emotional state cause a perception of greater pain. ${ }^{17}$ We can state that the diaphragm has an influence on baroreceptors and the perception of pain and vice versa.

Diaphragm movement changes the body pressure, as it facilitates the venous return and lymphatic flow upward. ${ }^{2}$ This modulation of pressure influences the redistribution of blood. ${ }^{18}$ It is this action that probably determines the baroreceptors response and the reduced perception of pain, but there are no scientific texts, as yet, to substantiate this claim.

Recent scientific evidence highlights the ability to carry pain afferents by the vagus nerve, especially for visceral pain. It is generally believed that pain arising from the viscera is mediated exclusively by spinal afferents, because vagal afferents primarily convey interoceptive information, but do not contribute to the perception of pain. ${ }^{19}$ Studies have shown that vagal afferents respond to nociceptive mechanical and chemical stimulation from the visceral area and this leads to brain stem representation of nociceptive signals. ${ }^{19}$ We know that the NTS stimulates the vagus nerve. We can assume that a physiological function of the diaphragm muscle can somehow reduce the afferent nociceptive stimulation from the vagus nerve, or through adequate visceral pressure and/or proper functions of the viscera at the lowering of the diaphragm. ${ }^{20}$ There is no scientific evidence to confirm this reflection at this time.

An incorrect positioning of the diaphragm due to systemic or local pathological reasons, as in chronic obstructive pulmonary disease, previous laparoscopic surgery, cerebral ischemia, and somatic problems related to somatic disorders of the lumbar and sacroiliac joint and cervical spine, can be the source problems of pain, both locally and in visceral articulated functions. ${ }^{21-28}$ The causes of induced localized, somatic, or visceral or systemic pain may be varied. There are no studies that correlate these diseases and pain with exhaustive explanations directly related to the actions and functions of the diaphragm muscle. We can assume that the baroreceptors are not adequately stimulated due to an 
alteration of diaphragm mobility; this will lead to a greater feeling of pain. The same diaphragm can be a source of afferent pain probably because the phrenic nerve, a mixed nerve that carries motor and sensory information, shares information with the trigeminal nucleus spinae. ${ }^{2,29,30}$ The latter has a connection with the NTS, and there is speculation that this connection is the cause of pain from the diaphragm. ${ }^{31}$

The diaphragm has a phrenic center, consisting of a strong "V"-shaped connective component having a variable percentage of the amount of contractile tissue. ${ }^{32}$ The fascial system is richly innervated by proprioceptors, which may become a source of afferent pain, transforming in turn into nociceptors. ${ }^{33}$ The crural and connective area is populated by proprioceptors, and we can assume that alteration of the position and function of the respiratory muscle creates a condition of irritability of these proprioceptors and consequent occurrence of painful afferents. ${ }^{2}$ The right phrenic nerve penetrates the diaphragm at the level of the connective tissue of the phrenic center, while the left phrenic nerve penetrates the muscle area of the muscle; the right nerve has a faster electro conductivity than the left. ${ }^{32,34}$ We might suppose that if the position of the diaphragm is not physiological, the phrenic nerve will be stretched or irritated in different ways, causing nociceptive afferents, in the same way as irritation of a peripheral nerve from the surrounding tissues..$^{35,36}$

\section{Emotional respiration}

The diaphragm has many functions, including maintenance of the systemic biochemical and emotive equilibrium. ${ }^{37}$ The most important stimulus for the generation of respiration is provided by chemoreceptors that manage the biochemical equilibrium of the organism. ${ }^{37}$ Breathing is also affected by environmental conditions inside and outside the body, and it is thought to have other ways of neural stimulation in respect of chemoreceptor stimulation. ${ }^{37}$ The action of the diaphragm is not controlled solely by metabolic demands, but also by emotional states, such as sadness, fear, anxiety, and anger. ${ }^{37}$ The interaction between respiration and emotion involves a complex interaction between the brain stem and the brain centers such as the limbic area and cortex. ${ }^{37,38}$ The life of the person and his/her personality influence the behavior of the diaphram. ${ }^{37}$ The amygdala, which is part of the limbic system, is reciprocally connected to each of the respiratory areas, just as the medulla oblongata, and is considered the most important area that manages emotive breathing. ${ }^{37,39}$ The amygdala is divided into three areas - the basolateral, cortical, and central areas; the basolateral amygdala sends efferents to the central area, which in direct and indirect mode sends signals to the hypothalamus and the brainstem trunk. ${ }^{39}$ The amygdala is stimulated by dopamine production from tegmental area of the midbrain, and recent studies on animal models show that the dopamine that reaches the amygdala manages emotive respiration. ${ }^{39}$ The amygdala efferents pass through the areas connected to respiration, such as the NTS and correlated structures. ${ }^{39}$

The sensations of breathing are the result of two cortical and subcortical processes: a discriminative process that assesses spatial awareness, timing, and intensity of breath; and an affective process that assesses the emotional feelings of the respiratory components. ${ }^{9}$

Breathing stimulates the mechanoreceptors of the diaphragm and the visceroceptors of the organs moved by inhalation-exhalation, which constitute the interception mechanism. ${ }^{9,40}$ The latter constitutes the awareness of the condition of the body based on the information derived directly from the body. ${ }^{40}$ The ascent and descent of the diaphragm also stimulates the skin and organs of the mediastinum, and the complexity of afferent structures determines the different representations of central respiration. ${ }^{2,41}$

The afferent pathways of interoception project to the autonomous medulla centers and the brain stem, where they are split into the anterior cingulate cortex and the dorsal posterior insula, thanks to the extension of the thalamus cortical. ${ }^{42}$ Interoception can modulate the representation of exteroceptive body, as well as the tolerance to pain; dysregulation of the pathways that manage or stimulate interoception could cause a distortion of body image, affecting emotion. $^{42,43}$

The same anxious state alters afferent pathways related to breathing (receptors that adapt quickly and slowly, type $\mathrm{C}$ bronchial and lung receptors, high-threshold-type A $\delta$ receptors, cough receptors, and neuroepithelial receptors), amplifying one or more receptor pathways related to respiration. ${ }^{41}$ We can strongly assume that an altered function of the diaphragm can adversely affect the patient's emotional state, probably because the interoceptive pathways stimulated by breathing are managed as motivational information, as these pathways of information are bidirectional. ${ }^{41}$

The request for challenging breathing, as in a physical exercise, could cause a strong emotional reaction in anxious people, making them relive symptoms and psychological disorders, worsening the respiratory function. ${ }^{41}$ We know that patients with respiratory ailments or chronic pain suffer from anxiety disorders, and this condition implies that the function of the diaphragm can worsen with physical exertion 
without taking into account also the emotional aspect of the patient. $^{44,45}$

Interoception is also linked to the visceral movement caused by respiration, and we know that people more susceptible to visceral afferents show more intense emotions. ${ }^{46}$ A probable cause could be related to the neurogenic neuroinflammation spreading inflammatory substances in the spinal cord, involving more areas and making them more likely to respond to a minimum of stimuli, making the afferential paths related to interception a further cause for anxiety and pain. ${ }^{46}$ This event could lead to a pleiotropic effect of functional impairment of the connective tissue, further destabilizing the functioning of the diaphragm. ${ }^{46}$ This neurogenic neuroinflammation is found in respiratory diseases, such as allergies of the upper airway and chronic diseases (such as chronic obstructive pulmonary disease), as well as in conditions of chronic pain. ${ }^{47-49}$ One could speak of "emotional allodynia breathing" when a breath that stimulates interoceptive afferent pathways causes symptoms linked to psychological aspects.

The innervation of the diaphragm muscle may be responsible, directly and indirectly, for the emotional state of the person. Afferent stimulation to the NTS by the phrenic nerve could affect the emotional response, because the NTS handles visceral afferents and has a close relationship with the same nerve ${ }^{50,51}$ Confirmation of this assumption is expected. The phrenic nerve has subdiaphragmatic ganglia with a relationship with the adrenal gland. ${ }^{52,53}$ The significance of this relationship is unknown. But we know that the adrenal gland and the hypothalamus-pituitary axis (HPA) affects the feeling of pain and the intensity of emotional aspects. ${ }^{54,55}$ The possible existence of a cause-effect on the HPA axis and the direct intervention of the phrenic nerve with the emotional aspect and the intensity of the perceived pain threshold need more studies and research. Further research is expected. The vagus nerve affects the emotional spectrum and respiratory rate, probably always through the NTS. We do not have exhaustive knowledge of whether or not there is also a bidirectional response to emotional conditions by the diaphragm from the vagus nerve. ${ }^{56-58}$

It is undeniable that a respiratory disorder can alter the emotional picture, similar to depression and anxiety, and it is equally true that an altered emotional state worsens the respiratory function. ${ }^{59,60}$ Considering also the emotional side during manual treatment, such as manual therapy or an osteopathic treatment, would probably be more helpful for the patient.

\section{Conclusion}

The diaphragm influences the intensity of the pain and there is an indisputable association with emotions and experience acknowledged by the patient. Every professional such as the doctor, the manual operator, and the psychologist ends their sphere of competence where the other professional's competence begins. This reflection allows for a multidisciplinary approach to the diaphragm, and collaboration of various medical and nonmedical figures, with the ultimate goal to regain or improve patient's physical and mental well-being.

\section{Disclosure}

The authors report no conflicts of interest in this work.

\section{References}

1. Harper CJ, Shahgholi L, Cieslak K, Hellyer NJ, Strommen JA, Boon AJ. Variability in diaphragm motion during normal breathing, assessed with B-mode ultrasound. J Orthop Sports Phys Ther. 2013;43(12):927-931.

2. Bordoni B, Zanier E. Anatomic connections of the diaphragm: influence of respiration on the body system. $J$ Multidiscip Healthc. 2013;6:281-291.

3. Hamaoui A, Hudson AL, Laviolette L, Nierat MC, Do MC, Similowski T. Postural disturbances resulting from unilateral and bilateral diaphragm contractions: a phrenic nerve stimulation study. J Appl Physiol (1985). 2014;117(8):825-832.

4. Bradley H, Esformes J. Breathing pattern disorders and functional movement. Int J Sports Phys Ther. 2014;9(1):28-39.

5. Chaitow L, Gilbert C, Morrison D. Recognizing and Treating Breathing Disorders. A Multidisciplinary Approach. Oxford, England: Churchill Livingstone; 2013.

6. Shen MJ, Zipes DP. Role of the autonomic nervous system in modulating cardiac arrhythmias. Circ Res. 2014;114(6):1004-1021.

7. Critchley HD, Nicotra A, Chiesa PA, et al. Slow breathing and hypoxic challenge: cardiorespiratory consequences and their central neural substrates. PLoS One. 2015;10(5):e0127082.

8. Evans KC, Dougherty DD, Schmid AM, et al. Modulation of spontaneous breathing via limbic/paralimbic-bulbar circuitry: an event-related fMRI study. Neuroimage. 2009;47(3):961-971.

9. Davenport PW, Vovk A. Cortical and subcortical central neural pathways in respiratory sensations. Respir Physiol Neurobiol. 2009;167(1):72-86.

10. Kuehn E, Mueller K, Lohmann G, Schuetz-Bosbach S. Interoceptive awareness changes the posterior insula functional connectivity profile. Brain Struct Funct. Epub 2015 Jan 23.

11. Reyes Del Paso GA, Muñoz Ladrón de Guevara C, Montoro CI. Breathholding during exhalation as a simple manipulation to reduce pain perception. Pain Med. Epub 2015 Apr 30.

12. Gray MA, Minati L, Paoletti G, Critchley HD. Baroreceptor activation attenuates attentional effects on pain-evoked potentials. Pain. 2010;151(3):853-861.

13. Nielsen R, Nikolajsen L, Krøner K, et al. Pre-operative baroreflex sensitivity and efferent cardiac parasympathetic activity are correlated with post-operative pain. Acta Anaesthesiol Scand. 2015;59(4):475-485.

14. Reyes del Paso GA, Montoro C, Muñóz Ladrón de Guevara C, Duschek S, Jennings JR. The effect of baroreceptor stimulation on pain perception depends on the elicitation of the reflex cardiovascular response: evidence of the interplay between the two branches of the baroreceptor system. Biol Psychol. 2014;101:82-90. 
15. Duschek S, Werner NS, Reyes Del Paso GA. The behavioral impact of baroreflex function: a review. Psychophysiology. 2013;50(12): 1183-1193.

16. Hagman C, Janson C, Emtner M. Breathing retraining-a five-year follow-up of patients with dysfunctional breathing. Respir Med. 2011;105(8):1153-1159.

17. Vietri J, Otsubo T, Montgomery W, Tsuji T, Harada E. The incremental burden of pain in patients with depression: results of a Japanese survey. BMC Psychiatry. 2015;15:104.

18. Petersen LG, Carlsen JF, Nielsen MB, Damgaard M, Secher NH. The hydrostatic pressure indifference point underestimates orthostatic redistribution of blood in humans. J Appl Physiol (1985). 2014;116(7):730-735.

19. Chen SL, Wu XY, Cao ZJ, et al. Subdiaphragmatic vagal afferent nerves modulate visceral pain. Am J Physiol Gastrointest Liver Physiol. 2008;294(6):G1441-G1449.

20. Morton D, Callister R. Exercise-related transient abdominal pain (ETAP). Sports Med. 2015;45(1):23-35.

21. Priori R, Aliverti A, Albuquerque AL, Quaranta M, Albert P, Calverley PM. The effect of posture on asynchronous chest wall movement in COPD. J Appl Physiol (1985). 2013;114(8):1066-1075.

22. HajGhanbari B, Garland SJ, Road JD, Reid WD. Pain and physical performance in people with COPD. Respir Med. 2013;107(11): 1692-1699.

23. Di Massa A, Avella R, Gentili C. Respiratory dysfunction related to diaphragmatic shoulder pain after abdominal and pelvic laparoscopy. Minerva Anestesiol. 1996;62(5):171-176.

24. Park GY, Kim SR, Kim YW, et al. Decreased diaphragm excursion in stroke patients with dysphagia as assessed by M-mode sonography. Arch Phys Med Rehabil. 2015;96(1):114-121.

25. Oh H, Seo W. A comprehensive review of central post-stroke pain. Pain Manag Nurs. 2015;16(5):804-818.

26. Kolar P, Sulc J, Kyncl M, et al. Postural function of the diaphragm in persons with and without chronic low back pain. J Orthop Sports Phys Ther. 2012;42(4):352-362.

27. O'Sullivan PB, Beales DJ. Changes in pelvic floor and diaphragm kinematics and respiratory patterns in subjects with sacroiliac joint pain following a motor learning intervention: a case series. Man Ther. 2007;12(3):209-218.

28. Yeampattanaporn O, Mekhora K, Jalayondeja W, Wongsathikun J. Immediate effects of breathing re-education on respiratory function and range of motion in chronic neck pain. J Med Assoc Thai. 2014;97(suppl 7): S55-S59.

29. Blows WT. Diaphragmatic cramp as a possible cause of noncardiac chest pain and referred mandibular pain. $J$ Neurosci Nurs. 1999;31(3):187-190.

30. Wolf SG. Diaphragmatic spasm: a neglected cause of dyspnoea and chest pain. Integr Physiol Behav Sci. 1994;29(1):74-76.

31. Maniyar FH, Sprenger T, Schankin C, Goadsby PJ. The origin of nausea in migraine-a PET study. J Headache Pain. 2014;15:84.

32. du Plessis M, Ramai D, Shah S, Holland JD, Tubbs RS, Loukas M. The clinical anatomy of the musculotendinous part of the diaphragm. Surg Radiol Anat. 2015; 37(9):1013-1020.

33. Bordoni B, Zanier E. Clinical and symptomatological reflections: the fascial system. J Multidiscip Healthc. 2014;7:401-411.

34. Luo YM, Moxham J, Polkey MI. Diaphragm electromyography using an oesophageal catheter: current concepts. Clin Sci (Lond). 2008;115(8):233-244.

35. Rowe PC, Fontaine KR, Violand RL. Neuromuscular strain as a contributor to cognitive and other symptoms in chronic fatigue syndrome: hypothesis and conceptual model. Front Physiol. 2013;4:115.

36. Rickett T, Connell S, Bastijanic J, Hegde S, Shi R. Functional and mechanical evaluation of nerve stretch injury. J Med Syst. 2011;35(5):787-793

37. Homma I, Masaoka Y. Breathing rhythms and emotions. Exp Physiol. 2008;93(9):1011-1021.
38. Masaoka Y, Izumizaki M, Homma I. Where is the rhythm generator for emotional breathing? Prog Brain Res. 2014;209:367-377.

39. Sugita T, Kanamaru M, Iizuka M, et al. Breathing is affected by dopamine D2-like receptors in the basolateral amygdala. Respir Physiol Neurobiol. 2015;209:23-27.

40. Domschke K, Stevens S, Pfleiderer B, Gerlach AL. Interoceptive sensitivity in anxiety and anxiety disorders: an overview and integration of neurobiological findings. Clin Psychol Rev. 2010;30(1):1-11.

41. Paulus MP. The breathing conundrum-interoceptive sensitivity and anxiety. Depress Anxiety. 2013;30(4):315-320.

42. Tsay A, Allen TJ, Proske U, Giummarra MJ. Sensing the body in chronic pain: a review of psychophysical studies implicating altered body representation. Neurosci Biobehav Rev. 2015;52: 221-232.

43. Garfinkel SN, Critchley HD. Interoception, emotion and brain: new insights link internal physiology to social behaviour. Commentary on: "Anterior insular cortex mediates bodily sensibility and social anxiety" by Terasawa et al. (2012). Soc Cogn Affect Neurosci. 2013;8(3):231-234.

44. Parreira VF, Kirkwood RN, Towns M, et al. Is there an association between symptoms of anxiety and depression and quality of life in patients with chronic obstructive pulmonary disease? Can Respir J. 2015;22(1):37-41.

45. Bair MJ, Wu J, Damush TM, Sutherland JM, Kroenke K. Association of depression and anxiety alone and in combination with chronic musculoskeletal pain in primary care patients. Psychosom Med. 2008;70(8):890-897.

46. Sinibaldi L, Ursini G, Castori M. Psychopathological manifestations of joint hypermobility and joint hypermobility syndrome/Ehlers-Danlos syndrome, hypermobility type: the link between connective tissue and psychological distress revised. Am J Med Genet C Semin Med Genet. 2015;169C(1):97-106.

47. Pisi G, Olivieri D, Chetta A. The airway neurogenic inflammation: clinical and pharmacological implications. Inflamm Allergy Drug Targets. 2009;8(3):176-181.

48. Shah JP, Thaker N, Heimur J, Aredo JV, Sikdar S, Gerber L. Myofascial trigger points then and now: a historical and scientific perspective. $P M$ R. 2015;7(7):746-761.

49. Verma V, Sheikh Z, Ahmed AS. Nociception and role of immune system in pain. Acta Neurol Belg. 2014;115(3):213-220.

50. Zoccal DB, Furuya WI, Bassi M, Colombari DS, Colombari E. The nucleus of the solitary tract and the coordination of respiratory and sympathetic activities. Front Physiol. 2014;5:238.

51. Liu SX, Wei SJ, Zhou DB, Fan YL. Effects of microinjection of sodium glutamate and glycine into ventrolateral nucleus of tractus solitarius on the discharges of phrenic nerve in rabbits. Sheng Li Xue Bao. 1997;49(2):227-229.

52. Rusu MC. Considerations on the phrenic ganglia. Ann Anat. 2006;188(1):85-92.

53. Tubbs RS, Stetler W, Kelly DR, et al. Immunohistochemical study of the phrenic ganglion. Anat Sci Int. 2008;83(3):159-161.

54. Hoyer J, Burmann I, Kieseler ML, et al. Menstrual cycle phase modulates emotional conflict processing in women with and without premenstrual syndrome (PMS)--a pilot study. PLoS One. 2013;8(4):e59780.

55. Lacourt TE, Houtveen JH, Doornen LJ, et al. Biological and psychological predictors of visceral pain sensitivity in healthy premenopausal women. Eur J Pain. 2014;18(4):567-574.

56. Wang Z, Lü W, Qin R. Respiratory sinus arrhythmia is associated with trait positive affect and positive emotional expressivity. Biol Psychol. 2013;93(1):190-196.

57. Klarer M, Arnold M, Günther L, Winter C, Langhans W, Meyer U. Gut vagal afferents differentially modulate innate anxiety and learned fear. J Neurosci. 2014;34(21):7067-7076.

58. Frazier TW, Strauss ME, Steinhauer SR. Respiratory sinus arrhythmia as an index of emotional response in young adults. Psychophysiology. 2004;41(1):75-83. 
59. von Leupoldt A, Chan PY, Esser RW, Davenport PW. Emotions and neural processing of respiratory sensations investigated with respiratory-related evoked potentials. Psychosom Med. 2013;75(3): $244-252$.
60. Goodwin RD, Scheckner B, Pena L, Feldman JM, Taha F, Lipsitz JD. A 10-year prospective study of respiratory disease and depression and anxiety in adulthood. Ann Allergy Asthma Immunol. 2014;113(5): $565-570$.

\section{Publish your work in this journal}

The Journal of Multidisciplinary Healthcare is an international, peerreviewed open-access journal that aims to represent and publish research in healthcare areas delivered by practitioners of different disciplines. This includes studies and reviews conducted by multidisciplinary teams as well as research which evaluates the results or conduct of such teams or healthcare processes in general. The journal covers a wide range of areas and welcomes submissions from practitioners at all levels, from all over the world. The manuscript management system is completely online and includes a very quick and fair peer-review system. Visit http://www.dovepress.com/testimonials.php to read real quotes from published authors.

Submit your manuscript here: http://www.dovepress.com/journal-of-multidisciplinary-healthcare-journal 